\title{
Análise do uso da terra e da estrutura da paisagem do município de Porto Esperidião/MT
}

\begin{abstract}
No estado de Mato Grosso as divisões territoriais não foram constituídas a partir de um planejamento ambiental e espacial, desconsiderando as diferenças regionais e as peculiaridades das diversas microrregiões. A paisagem foi sendo alterada no decorrer dos anos, na medida em que a atividade econômica demandava a expansão de área para o seu desenvolvimento. Diante do exposto objetivou-se realizar a análise espaço-temporal da estrutura da paisagem do município de Porto Esperidião-MT, na perspectiva da geração de informações que contribuam no planejamento e na gestão ambiental municipal. 0 trabalho foi executado através das seguintes etapas: levantamentos de bases cartográficas nos projetos Radambrasil (1982) e Probio (1997); registro de imagens, recorte, segmentação, classificação digital de imagens orbitais, quantificação dos dados e elaboração dos mapas temáticos. Os resultados mostram alterações em todas as classes de vegetação durante os últimos 29 anos (1982-2011), ocorrendo diminuição de 54,77\% da vegetação nativa e aumento de 54,22\% de uso da terra, principalmente vinculado as pastagens para pecuária bovina. Relativo à estrutura da paisagem municipal constatou-se no período analisado que o uso antrópico contribuiu para a fragmentação da vegetação natural, sendo a matriz em 1982 constituída pela vegetação e em 2002 e 2011 pela pastagem. Concluiu-se que no período investigado entre os anos de 1982 e 2011 a vegetação natural de Porto Esperidião foi suprimida principalmente em função do desenvolvimento da atividade agropecuária, acarretando diminuição na vegetação dos biomas presentes e aumento no número de fragmentos, consequentemente reduzindo a biodiversidade de fauna e flora e impactando a conservação ambiental.
\end{abstract}

Palavras-chave: Conservação Ambiental; Biogeografia; Agricultura; Pecuária; Geotecnologias.

\section{Land use and landscape structure analysis of municipality Porto Esperidião - Mato Grosso state}

\begin{abstract}
In Mato Grosso State the territorial divisions were not constituted based on environmental and spatial planning, disregarding the regional differences and the peculiarities of the different micro-regions. The landscape was changed over the years, as the economic activity demanded the areal expansion for its development. In view of that, the objective of this study was to perform the space-time analysis of the landscape structure of the Porto Esperidião municipality, aiming to generate information which would contribute to its environmental management. The work was carried out in the following steps: surveys of cartographic bases of Projects Radambrasil (1982) and Probio (1997); Image registration; Clipping; Segmentation; Digital classification of satellite images; Quantification of data and elaboration of thematic maps. The results show changes in all vegetation classes during the last 29 years (1982-2011), with a $54.77 \%$ decrease of the original vegetation and a $54.22 \%$ increase of land use, mainly related to livestock. As for the structure of the municipal landscape, it was observed that during the period analyzed, the land use contributed to the fragmentation of the natural vegetation. The matrix in 1982 constituted by vegetation and in 2002 and 2011 by pasture. It was concluded that during the period investigated, between 1982 and 2011, the natural vegetation of Porto Esperidião was suppressed mainly due to the development of agricultural activity, resulting in a decrease of vegetation from the original biomes, and an increase in the number of fragments, reducing consequently the biodiversity of Fauna and Flora and impacting environmental conservation.
\end{abstract}

Keywords: Environmental Conservation; Biogeography; Agriculture; Livestock; Geotechnologies.

Topic: Química Agrícola e Ambiental

Reviewed anonymously in the process of blind peer

Divino Alves Cebalho

Universidade do Estado de Mato Grosso, Brasil

http://lattes.cnpq.br/2250870042959621

divinoalves9118@outlook.com

Miriam Raquel da Silva Miranda

Universidade do Estado de Mato Grosso, Brasil

http://lattes.cnpq.br/0076499327484052

miriamraquel18@gmail.com

Tamires da Silva Machado

Universidade do Estado de Mato Grosso, Brasil

http://lattes.cnpq.br/6186601473493125

tamiresagronomia@gmail.com
Received: 18/04/2016

Approved: 20/05/2016

\author{
Sandra Mara Alves da Silva Neves \\ Universidade do Estado de Mato Grosso, Brasil \\ http://lattes.cnpq.br/6430066425008976 \\ ssneves@unemat.br \\ Ronaldo José Neves \\ Universidade do Estado de Mato Grosso, Brasil \\ http://lattes.cnpq.br/5794831112557727 \\ hellentortorelli@gmail.com
}

Referencing this:

CEBALHO, D. A.; MIRANDA, M. R. S.; MACHADO, T. S.; NEVES, S. M. A S.; NEVES, R. J.. Análise do uso da terra e da estrutura da paisagem do município de Porto Esperidião/MT. Revista Ibero-Americana de

Ciências Ambientais, v.8, n.1, p.179-193, 2017. DOI:

http://doi.org/10.6008/SPC2179-6858.2017.001.0016 


\section{INTRODUÇÃO}

O processo de ocupação do território brasileiro tem suas características próprias, conduzindo-o para uma divisão territorial interna, que define diferentes ritmos e graus de crescimento econômico (ABREU, 2001). No Mato Grosso as divisões territoriais não foram constituídas a partir de um planejamento ambiental e espacial, desconsiderando as diferenças regionais e as peculiaridades das diversas microrregiões. O Estado apresenta características que formam o retrato da sua diversidade demográfica e ambiental (CUNHA, 2006).

A paisagem foi sendo alterada no decorrer dos anos, na medida em que a atividade econômica demandava a expansão de área para o seu desenvolvimento. De acordo com Bertrand (1971) a paisagem é resultado da combinação de elementos físicos, biológicos e antrópicos que, reagindo uns sobre os outros, fazem dela um conjunto único e indissociável, em perpetua evolução.

Bohrer (2000) descreve que os usos atuais da terra podem determinar a exclusão em curto prazo da aptidão para outros tipos de utilização futura, assim as condições socioeconômicas influenciarão na análise dos níveis de insumos a serem incorporados ao sistema produtivo. Portanto, é necessário que este seja reavaliado periodicamente, devido às novas evidências científicas, inovações tecnológicas e mudanças na realidade socioeconômica regional, no intuito de se evitar a degradação dos componentes ambientais.

A degradação ambiental é geralmente acarretada pela pressão derivada do crescimento populacional e econômico, associada à inexistência de uma política de planejamento e gestão dos elementos naturais constituintes da paisagem. Isto requer uma série de atividades consideradas essenciais para encontrar os caminhos do desenvolvimento sustentável e o manejo adequados recursos ainda existentes (CUNHA e GUERRA, 2003).

Para analisar uma paisagem espacializada se faz necessário proceder a sua identificação, descrição e classificação dos componentes que constituem sua taxinomia (SIQUEIRA; CASTRO; FARIA, 2013). Uma forma de realização dessa análise é por meio de métricas da paisagem, cujos resultados podem ser utilizados como indicadores de qualidade de fragmentos (MELLO, 2012), permitindo análise das mudanças estruturais, determinação das relações entre os processos funcionais e os padrões e a avaliação dos efeitos da fragmentação na conservação ambiental das paisagens (VALENTE; VETORAZZI, 2002).

Portanto, na análise da paisagem, tem-se que considerar as relações entre o homem e o ambiente, considerando as modificações decorrentes do processo de ocupação. Nesse sentido, Schneider e Tartaruga (2004) usaram técnicas informatizadas de análise espacial para obter elevado destaque na compreensão do dinamismo do uso e da ocupação das terras.

O uso de geotecnologias, dentre as quais o Sensoriamento Remoto e os Sistemas de Informações Geográficas, são instrumentos consagrados de análise e modelagem do espaço geográfico (GONÇALVES et al., 2012), para diversos fins, como a análise das mudanças estruturais da paisagem para avaliar os efeitos da fragmentação na conservação ambiental das paisagens. 
Nesse sentido, objetivou-se realizar a análise espaço-temporal da estrutura da paisagem do município de Porto Esperidião-MT, na perspectiva da geração de informações que contribuam para o planejamento e a gestão ambiental municipal.

\section{METODOLOGIA}

\section{Área de Estudo}

Esta pesquisa foi desenvolvida no município mato-grossense de Porto Esperidião (Figura 1), com área territorial de 5.809,015 km² (IBGE, 2015), pertencente à região sudoeste de planejamento do estado de Mato Grosso (MATO GROSSO, 2012). Possui uma população de aproximadamente 11.031 habitantes (IBGE, 2010), sendo que destes $61,9 \%$ vivem na zona rural.

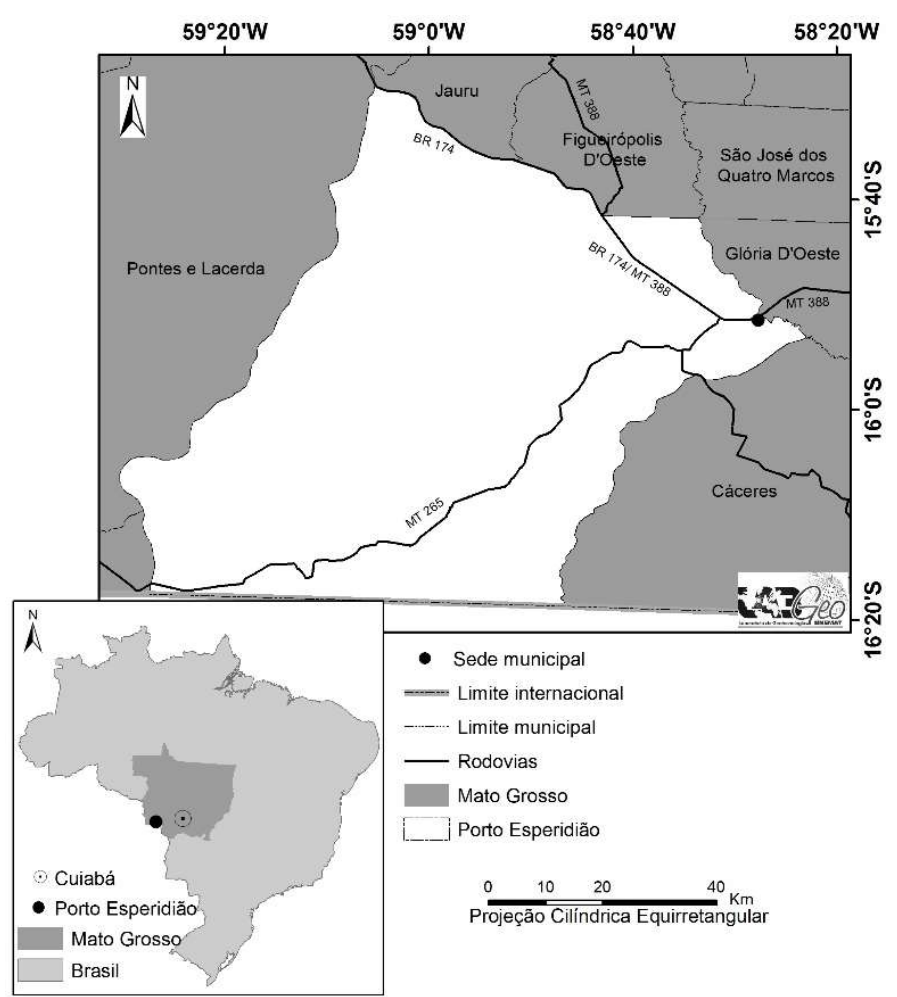

Figura 1: Município de Porto Esperidião/MT no contexto brasileiro. Elaboração: os autores, 2016.

No município são encontrados três biomas, sendo que $41,6 \%$ de sua extensão é Pantanal, $22,4 \%$ Cerrado e 36\% Amazônia segundo o Programa Nacional para a Conservação e Utilização Sustentável da Diversidade Biológica - PROBIO (BRASIL, 2007).

Duas bacias estão presentes no município, a do rio Jauru e Los Patos, afluentes da Bacia do Alto Paraguai, onde está contido o Pantanal mato-grossense.

O clima de Porto Esperidião é do tipo Tropical subúmido com temperatura média anual variando de

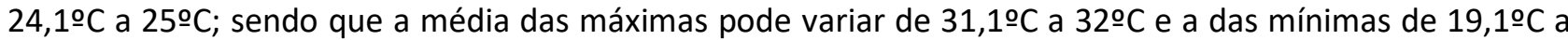
20C. A pluviosidade média anual oscila entre $1400 \mathrm{~mm}$ a $1600 \mathrm{~mm}$ anuais (TARIFA, 2011). 
O Índice de Desenvolvimento Humano Municipal (IDH-M) em 2010 foi de 0,652 (PNUD, 2013) e a sua economia é baseada na atividade agropecuária, a qual responde por $48,3 \%$ do PIB municipal. A base da economia municipal é a pecuária, seguida pela atividade agrícola (IBGE, 2016).

\section{Procedimentos Metodológicos}

O trabalho contou com o cumprimento das seguintes etapas: levantamentos de bases cartográficas geradas nos Projetos Radambrasil (BRASIL, 1982) e da Conservação e Utilização Sustentável da Diversidade Biológica Brasileira - Probio (BRASIL, 2007); Processamento digital de imagens de sensoriamento remoto orbital (registro, recorte, segmentação, classificação supervisionada e pós-classificação), trabalho de campo e de gabinete para quantificação dos dados e elaboração dos mapas temáticos para subsidiar a análise e discussão dos resultados. A seguir serão apresentadas as etapas elencadas.

As bases cartográficas foram obtidas nos mapeamentos gerados pelos projetos Radambrasil (BRASIL, 1982a; BRASIL, 1982b) e do Probio (BRASIL, 2007). No projeto Radambrasil o mapa de cobertura vegetal foi gerado a partir da interpretação das imagens de radar, enquanto que no do Probio foi utilizado imagens Landsat TM 5, do ano de 2002.

Os mapas resultantes de ambos os projetos foram sistematizados em folhas de 1:250.000 e disponibilizados na extensão shapefile. As folhas que recobrem o município de Porto Esperidião de ambos os projetos foram recortadas pela base cartográfica digital municipal (máscara), obtidas no sitio do Instituto Brasileiro de Geografia e Estatística (IBGE).

Os procedimentos metodológicos de processamento digital de imagem adotados iniciaram pelo registro das imagens do satélite Landsat 5, sensor TM, órbitas/pontos 227/70 e 228/70 de 2011 no Sistema de Processamento de Informações Georreferenciadas (SPRING) do Instituto Nacional de Pesquisas Espaciais (INPE) (CÂMARA et al., 1996). O registro destas consistiu na obtenção de 20 pontos de controle por imagem, considerando a distribuição destes por toda a superfície da imagem. Na sequência foi realizado o mosaico das imagens, com posterior recorte que utilizou a base cartográfica digital do município como máscara.

A segmentação pautou-se na utilização do método de crescimento de regiões, por meio do método exploratório, utilizando os limiares de similaridade 15 e área 15 . O arquivo digital da classificação supervisionada gerado no Spring foi exportado no formato shapefile, e no ArcGis (ESRI, 2017) foram elaboradas as quantificações e os layouts dos mapas.

As métricas da paisagem foram geradas no software Fragstats, versão 3.3 (MCGARIGAL e MARKS, 1995), que quantifica a fragmentação da paisagem, fornecendo valores quantitativos de extensão de área e de distribuição espacial de fragmentos, a partir das informações geradas via mapa temático ou de uma imagem de satélite (VOLOTÃO, 1998). No Fragstats, foram calculadas as métricas (estatísticas) de paisagem, cujas fórmulas encontram-se apresentadas no Quadro 1. 
Quadro 1: Métricas da paisagem utilizadas na análise do município de Porto Esperidião/MT.

\begin{tabular}{|c|c|c|}
\hline Métrica & Descrição & Fórmulas \\
\hline CA & Área de todos os fragmentos da classe. & $C A=\sum_{J=1}^{n} a_{i j} \frac{1}{10.000} a_{i j}$ área $\left(\mathrm{m}^{2}\right)$ da mancha $i j$ \\
\hline NP & Número de fragmentos existentes na classe. & $N P=n_{i} n_{i}$ número de manchas do tipo (classe)i na paisagem \\
\hline ENN_MN & $\begin{array}{l}\text { Soma de todas as distancias entre cada } \\
\text { fragmento e o vizinho mais próximo da } \\
\text { mesma classe, dividido pelo número de } \\
\text { fragmentos da classe. }\end{array}$ & $\begin{array}{l}\text { ENN } \\
=h_{i j} h_{i j \text { distância da mancha } i j \text { à mancha de vizinhança mais próxima }} \quad \text { como mesmo tipo de classe, baseada na distância borda a borda }\end{array}$ \\
\hline $\begin{array}{l}\text { CIRCLE_M } \\
\mathrm{N}\end{array}$ & $\begin{array}{l}\text { Dado pela soma do perímetro de cada } \\
\text { fragmento dividido pela raiz quadrada da } \\
\text { área, e ajustada para o padrão circular (para } \\
\text { polígonos), dividido pelo número de } \\
\text { fragmentos da classe. }\end{array}$ & $\begin{array}{l}F F \\
=\frac{p_{i j}}{\operatorname{minp}_{i j}} p_{i j} \begin{array}{c}\text { perímetro do fragmento em relação ao número de células; } \\
\text { minp } i j \text { perímetro mínimo em relação ao número de células }\end{array}\end{array}$ \\
\hline
\end{tabular}

Fonte: McGarigal e Marks (1995). Organização: os autores (2016).

Os resultados obtidos dos procedimentos apresentados foram analisados a luz de diversos referenciais bibliográficos, possibilitando o estabelecimento da discussão dos resultados.

\section{Resultados e Discussão}

Com a ocupação do município de Porto Esperidião no decorrer dos anos a vegetação foi sendo suprimida e os usos da terra aumentando, principalmente para a agricultura, pecuária e a área urbana (Tabela 1). É possível afirmar que vegetação foi a classe mais expressiva em 1982 e 2002 diferentemente do ano de 2011, em que se destacou a classe de uso.

Tabela 1: Cobertura vegetal e uso da terra do município de Porto Esperidião/MT no período de 1982 a 2011.

\begin{tabular}{|c|c|c|c|}
\hline \multirow{2}{*}{ Classes } & \multicolumn{3}{|c|}{ Área (ha) } \\
\hline & 1982 & 2002 & 2011 \\
\hline Vegetação & $580.900,50$ & $392.840,50$ & $259.501,92$ \\
\hline Uso Antrópico & - & $187.850,47$ & $320.105,10$ \\
\hline Influência Urbana & - & 210,53 & 412,34 \\
\hline Água & - & - & 881,14 \\
\hline Total & $580.900,50$ & $580.900,50$ & $580.900,50$ \\
\hline
\end{tabular}

No ano de 1982 em Porto Esperidião não foi registrada supressão vegetal (Figura 2a). Este era distrito de Cáceres por isso não há registro do número de habitantes, a população residia principalmente em sítios e fazendas. Em 2002 a vegetação natural estava presente em 67,63\% do município, resultando no uso da terra de 32,34\% em virtude do desenvolvimento da pecuária, construção de represas e a expansão da área urbana, que neste ano representava $0,04 \%$ da área do município, devido a emancipação municipal ter ocorrido em 1986 (Figura 2b).

Possivelmente no decorrer de 20 anos (1982-2002) o cumprimento das leis ambientais, principalmente as contidas no código florestal (BRASIL, 1965), não tenham sido devidamente cumpridas. Ao analisar a Figura 2c, foi possível afirmar que o desmatamento da vegetação no município se deu no sentido nordeste-sul, sendo que as áreas a sudoeste se encontram recobertas por vegetação devido ao relevo movimentado. 

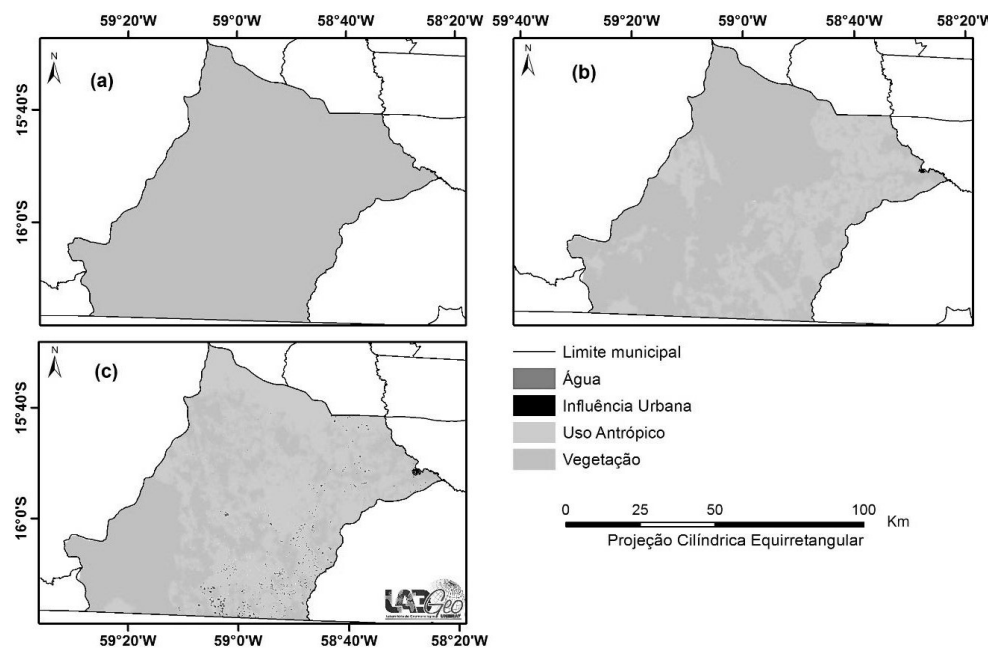

Figura 2: Cobertura vegetal e uso da terra do município de Porto Esperidião, nos anos de 1982 (a), 2002 (b) e 2011 (c).

No período de 2002 a 2011 verificou-se um menor percentual de supressão da vegetação, que totalizou 22,39\%. Esta situação pode ser atribuída ao cumprimento das legislações ambientais vigentes e ao aparato tecnológico disponibilizado aos órgãos fiscalizadores. Uma vez que a Secretaria de Meio Ambiente estadual (SEMA/MT) conta com o Cadastro de Ambiental Rural, que utiliza imagens do satélite SPOT para concessão de licenciamento de atividades, e o Instituto Brasileiro do Meio Ambiente e dos Recursos Naturais Renováveis (IBAMA) que tem recebido apoio para sua atuação na fiscalização, através de imagens de satélite do Sistema de Deteç̧ão de Desmatamentos em Tempo Real (Deter).

Entre 2002 e 2011 o uso aumentou aproximadamente 70\%, tendo em vista o processo de uso e ocupação do município, desmatamento, expansão urbana e principalmente a implementação de atividades agropecuárias.

A partir dos dados da Tabela 01 e das Figuras 2a, 2b e 2c pode-se verificar que a área urbana apresentou crescimento, sendo que entre os anos de 2002 e 2011 esta mais que duplicou em tamanho de área. Esse crescimento pode estar relacionado ao aumento de população municipal que segundo o censo passou de 8.586 habitantes em 1990 para 11.031 habitantes em 2010 (IBGE, 2016).

Como a classe água não foi mapeada nos anos de 1982 e 2002, somente no ano de 2011, não foi possível a realização da análise de sua dinâmica. Em suma, no decorrer de 29 anos ocorreu a supressão de 55,33\% da vegetação municipal, em função da agricultura, criação de animais e a expansão urbana, pois de acordo com Andrade e Souza (2008) houve o aumento no período de 1986 a 1998 da área desmatada (Cerrado, Floresta e Mata de galeria), nos municípios da sub-bacia hidrográfica do córrego das Pitas em Mato Grosso.

Na sequência deste artigo serão analisadas as dinâmicas da cobertura vegetal e uso da terra de forma detalhada, ao nível das formações vegetais e tipos de uso da terra. Ressalta-se que para a análise do ano de 1982 foram utilizadas as bases cartográficas do projeto Radambrasil (BRASIL, 1982), para o ano de 2002 os dados cartográficos do projeto Probio (BRASIL, 2007) e para o ano de 2011 o mapa gerado pelo LabGeo UNEMAT, cuja classificação utilizada foi a do Brasil (2007). As classificações da vegetação utilizadas foram 
distintas não houve compatibilização, sendo nesta pesquisa discutidas as classes conforme constam nas referidas fontes (Tabela 2).

Tabela 2: Formações vegetais presentes em Porto Esperidião nos anos de 1982, 2002 e 2011.

\begin{tabular}{|c|c|c|c|c|}
\hline \multirow{2}{*}{ Classe } & \multirow{2}{*}{ Formação } & \multicolumn{3}{|c|}{ Área (ha) } \\
\hline & & 1982 & 2002 & 2011 \\
\hline \multirow{9}{*}{ Vegetação } & Floresta aluvial & $15.322,82$ & $14.895,59$ & $34.608,34$ \\
\hline & Floresta submontana & $111.304,07$ & - & - \\
\hline & Savana arborizada & \multicolumn{2}{|c|}{ - $17.696,67$} & $14.122,40$ \\
\hline & Savana florestada & $208.934,54$ & $34.221,42$ & $75.514,52$ \\
\hline & Savana arborizada com floresta da galeria & $121.545,26$ & $23.673,68$ & - \\
\hline & Savana arborizada sem floresta de galeria & $111.823,02$ & $9.783,72$ & - \\
\hline & Savana gramíneo-lenhosa & & 760,49 & - \\
\hline & Savana parque & $11.970,79$ & $42.123,33$ & - \\
\hline & Savana/Floresta estacional decidual & - & $247.723,52$ & $135.256,66$ \\
\hline \multirow{4}{*}{ Uso Antrópico } & Agropecuária & - & $42.652,73$ & $225.995,16$ \\
\hline & Áreas degradadas por mineração & - & - & 109,38 \\
\hline & Pecuária & - & $147.158,82$ & $94.000,56$ \\
\hline & Influência urbana & - & 210,53 & 412,34 \\
\hline \multirow[t]{2}{*}{ Água } & Corpos d'água & - & - & 881,14 \\
\hline & Total & $580.900,50$ & $580.900,50$ & $580.900,50$ \\
\hline
\end{tabular}

A Floresta aluvial, denominada também por mata ciliar, ocorre nas áreas de acumulação inundáveis, principalmente ao longo da drenagem, no caso ao longo do rio Jauru e dos córregos Aguapeí, das Pitas e Santa Rita. As atividades humanas desenvolvidas em um trecho do rio podem causar desequilíbrios em sua dinâmica, pela construção de obras de engenharia como reservatórios, canalizações e outras, juntando estes fatores com os naturais como topografia, geologia, clima, solos e vegetação os desequilíbrios e a degradação podem ser potencializados (CUNHA e GUERRA, 2003).

As formações vegetais de Floresta aluvial e a Savana arborizada com floresta da galeria embora em menor percentual apresentam-se de alta relevância, considerando que estão associadas aos corpos hídricos, que não aparecem representadas no mapa, devido possivelmente pela vegetação em 1982 estar conservada, pela característica de intermitência dos cursos em ambiente de Cerrado e pequena largura dos canais, vindo a vegetação a recobrir os mesmos.

As áreas recobertas com Floresta aluvial decresceram entre 1982 e 2002 e o percentual de 2,64\% aumentou para 56,96\% em 2011 (Figura 5). O aumento da área de Floresta aluvial pode ter ocorrido devido no processo de elaboração do mapeamento em áreas ocupadas por outro tipo de formação florestal ter sido incorporadas a esta, decorrente da área de transição. Entretanto, o crescimento da área urbana contribui para o desmatamento dessa formação, uma vez que esta foi edificada à margem do rio Jauru, associada à expansão da atividade agropecuária, caracterizando um prejuízo a conservação dos recursos hídricos. Por ser de grande importância para biodiversidade a Floresta aluvial é considerada como Área de Preservação Permanente (APP), protegida pela Lei 12.727/2012, relativa ao Código Florestal, conforme segue:

I - as faixas marginais de qualquer curso d'água natural perene e intermitente, excluídos os efêmeros, desde a borda da calha do leito regular, em largura mínima de: (Incluído pela Lei no 12.727, de 2012).

a) 30 (trinta) metros, para os cursos d'água de menos de 10 (dez) metros de largura; 
b) 50 (cinquenta) metros, para os cursos d'água que tenham de 10 (dez) a 50 (cinquenta) metros de largura;

c) 100 (cem) metros, para os cursos d'água que tenham de 50 (cinquenta) a 200 (duzentos) metros de largura;

d) 200 (duzentos) metros, para os cursos d'água que tenham de 200 (duzentos) a 600 (seiscentos) metros de largura;

e) 500 (quinhentos) metros, para os cursos d'água que tenham largura superior a 600 (seiscentos) metros" (BRASIL, 2012, p. 2).

Segundo Miranda et al. (2014) a formação Floresta submontana é encontrada em áreas de encostas e serras, situada na cota altimétrica de 100 a $600 \mathrm{~m}$, de acordo com a latitude de $4^{\circ} \mathrm{N}$ até $16^{\circ} \mathrm{S}$; de 50 a 500 m entre os $16^{\circ}$ até os $24^{\circ}$ de latitude $S$; e de 30 a $400 \mathrm{~m}$ após os $24^{\circ}$ de latitude Sul (IBGE, 2012). Essa classe representou 19,16\% da cobertura vegetal do município em 1982 (Figura 3a), estando localizada na porção central do município.

A Savana arborizada possui estrutura baixa e aberta, sendo uma formação exclusiva de solos lixiviados e de baixa fertilidade (IBGE, 2012). Em 1982 a classe não foi mapeada; em 2002 foi constatado que esta compreendia apenas 2,56\% da área municipal, em comparação ao ano de 2011 verificou-se que houve aumento da área em $25,31 \%$, o que pode estar relacionado ao processo de mapeamento incorporando outras formações florestais a esta classe. Santos et al. (2002) corroboram ao afirmarem que este tipo de vegetação compreende uma área de transição entre campo limpo e cerradão, com presença de espécies herbáceas.

A Savana florestada (Cerradão) se caracteriza pela ausência de árvores emergentes, dossel uniforme e altura entre 10 e $12 \mathrm{~m}$, sendo que sua estrutura se assemelha àquela da Floresta estacional semidecidual, considerando os parâmetros área basal e cobertura (IBGE, 2012). Com a interpretação da Figura 3 e análise da Tabela 2 pode-se observar que a classe Savana florestada foi drasticamente devastada no período de 20 anos, tendo em vista que correspondia a 35,97\% da área territorial do município em 1982 e em 2002 foi reduzida para a 5,89\%, sendo que a agropecuária e pecuária foram as principais atividades responsáveis pela supressão da vegetação municipal. Verificou-se que esta foi a cobertura vegetal mais antropizada no decorrer do período de 1982-2011(29 anos), sendo suprimida em 176,68\%. Segundo Paiva et al. (2014) por possuir vegetação menos densa que a Savana arborizada e ter ocorrência de gramínea, nos locais de ocorrência pode ser utilizada como pasto natural.

A Savana arborizada com floresta de galeria e Savana arborizada sem floresta de galeria, são consideradas subformações da Savana arborizada, foram consideradas as mais impactadas, por terem sido completamente suprimidas. Em 1982 representavam respectivamente 20,92\% e 19,25\% da área do município, fato que pode ser atribuído ao desenvolvimento da pecuária (Figura 6). 

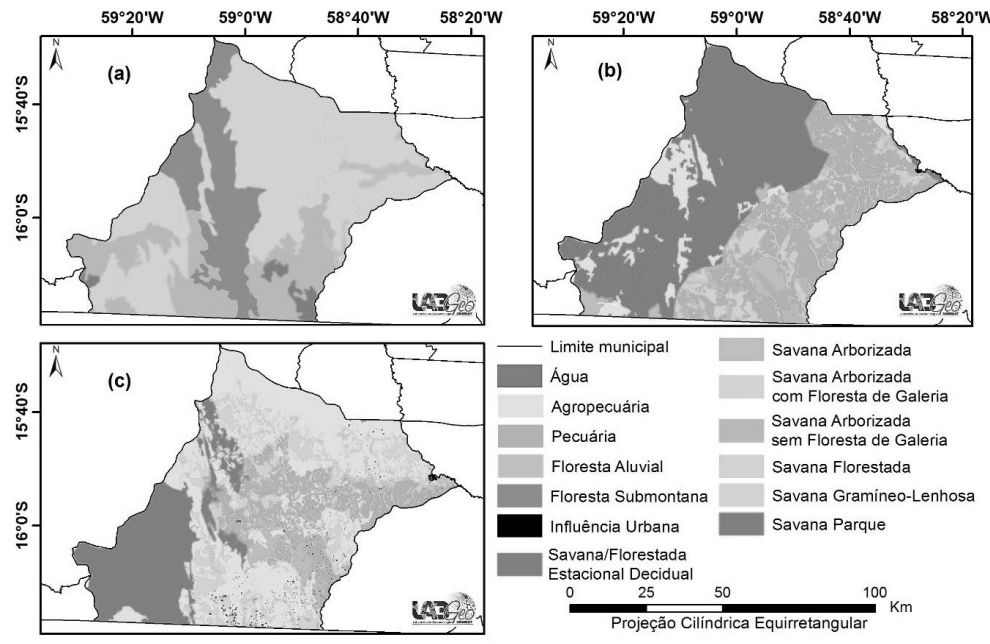

Figura 3: Formações vegetais e usos da terra em Porto Esperidião, em 1982 (a), 2002 (b) e 2011 (c).

A Savana gramíneo-lenhosa, conhecida regionalmente por campo sujo ou campo limpo, ocorre nas áreas baixas, periodicamente inundáveis, constituindo no período seco o domínio de campos, com predomínio de vegetação rasteira (IBGE, 2012). Essa classe ocorreu apenas no ano de 2002, onde compreendia $0,13 \%$ de área no município, ou seja, uma área pequena quando comparada as outras coberturas vegetais do município.

A formação Savana parque ocorre algumas vezes na região sudoeste matogrossense como feição de campos litossólicos e/ou rupestres (MIRANDA et al., 2013). Em 20 anos a classe cresceu 71,58\%, sendo um dos poucos tipos de vegetação a apresentar aumento de sua área de territorial.

Os Ecótonos representam o contato entre duas ou mais regiões fitoecológicas e se manifestam na forma de interpenetrações de espécies numa mesma área, conhecida ainda como Área de Tensão Ecológica (VELOSO et al., 1991). A Savana/Floresta estacional decidual foi o único tipo de Ecótono mapeado em 2002 quando totalizava 42,64\% da extensão territorial municipal, mas não foi representada em 1982 e em 2011 a classe foi suprimida em 83,15\%, evidenciando a intensificação do uso antrópico (Figura 7). Neves; Miranda; Neves (2015) observaram estudando a região sudoeste mato-grossense que esse tipo de vegetação é propicia a incêndios naturais devido as condições climáticas locais e a disponibilidade de material vegetal combustível.

Á Agropecuária foi a classe de maior representatividade em 2011, observando que houve um aumento de 81,13\% entre 2002 e 2011, sendo que esta atividade econômica estendeu seus domínios em virtude da supressão das classes. A atividade agropecuária pode ser considerada como responsável pelo comprometimento da conservação dos elementos da paisagem municipal, em virtude de seu avanço estar relacionado ao desmatamento de vastas áreas de vegetação nativa. Porém há de se ressaltar que a atividade é uma das bases da economia do município, respondendo por mais de 50\% do PIB (IBGE, 2006), desempenhando, portanto, papel fundamental na conjuntura econômica municipal.

A áreas degradadas por mineração estão situadas na comunidade Pau a Pique no município de Porto Esperidião, cujo garimpo está ainda em fase de implantação, o que representou 0,02\% da área do município em 2011. Segundo Mechi e Sanches (2010) uma área de mineração acarreta muitas consequências graves para os locais próximos a atividade, ocasiona a aceleração do processo de erosão do solo em virtude da 
retirada da vegetação para exploração do minério, além de causar processos de assoreamento e contaminação quando localizados próximos a cursos d'água.

O uso da terra para o desenvolvimento da pecuária ocupava $25,26 \%$ da extensão territorial do município no ano de 2002 (Figura 3b), entretanto apresentou redução de 56,55\% em relação a 2011. A atividade implicou na supressão da vegetação por ser realizada de forma extensiva, demandando grandes áreas para o plantio de pastagens, e em alguns casos, utilizada em conjunto com cultivos agrícolas (Figura 8). Esse comportamento da atividade ocorre também no estado de Mato Grosso, que sofreu e vem sofrendo constantes modificações ao longo dos anos, principalmente pela utilização de suas áreas nas culturas e criações de alto retorno econômico, como é o caso da pecuária (IBGE, 2006).

A área ocupada pela classe de Influência urbana é pequena (Figura 9), entre 2002 e 2011 aumentou 48,92\%. Fato que implica na incorporação de novas áreas são desmatadas para a construção de casas e ruas.

No ano 2011 verificou-se a presença de vários corpos de água (Figura 3c), que são utilizados principalmente na pecuária para dessedentação do gado. É comum o represamento dos cursos hídricos e a supressão da vegetação para atender este tipo de atividade econômica. Pois, segundo Silva e Souza (2008) a retirada da vegetação é destinada principalmente ao uso de práticas na agricultura, criação de animais e o crescimento urbano.

Os resultados descritos corroboram com as afirmações de Alves (2001), de que o processo de desflorestamento ocorre com maior intensidade na vizinhança de regiões abertas, levando a redução continua e até mesmo ao esgotamento das áreas de cobertura vegetal e das áreas de reserva legal. Na atualidade as questões econômicas prevalecem sobre as demandas da sustentabilidade e da conservação ambiental, sendo que devido a pecuária os proprietários de terras tem paulatinamente ampliando seu espaço em Porto Esperidião, em detrimento da vegetação. Em suma, a pecuária é uma atividade marcante na paisagem de Porto Esperidião, seguindo o padrão histórico da região sudoeste mato-grossense, cujas fazendas de criação de gado datam de mais de 80 anos atrás (Figura 4) (PORTO ESPERIDIÃO, 2013).

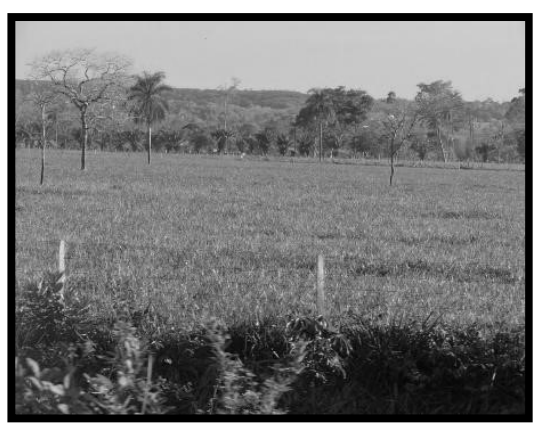

Figura 4: Pastagem preservada no município de Porto Esperidião/MT

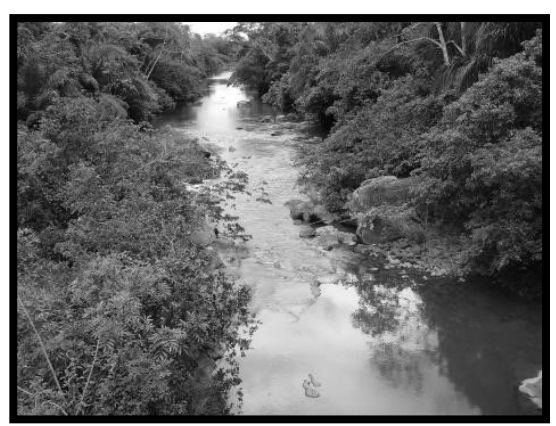

Figura 5: Floresta aluvial do rio Aguapeí na Fazenda Reunidas Boi Gordo.

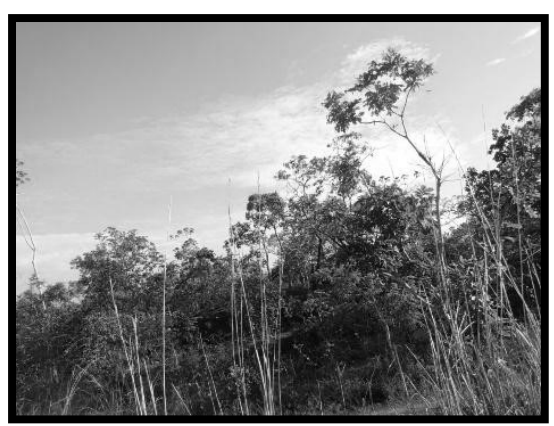

Figura 6: Savana arborizada (Cerrado) no município de Porto Esperidião. 


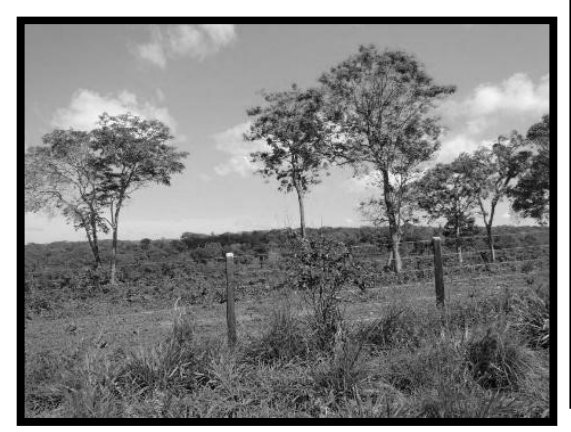

Figura 7: Zona de Transição entre Savana e a Floresta em Porto Esperidião.

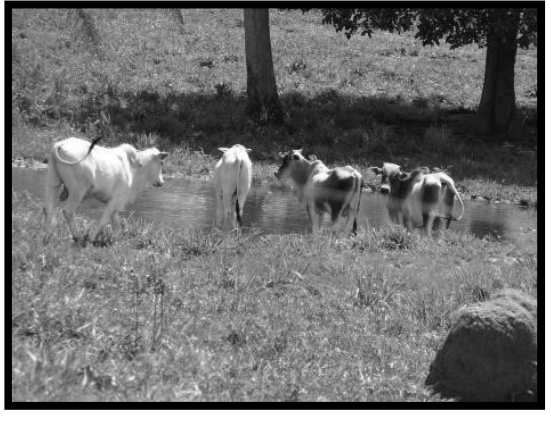

Figura 8: Pecuária extensiva no município de Porto Esperidião.

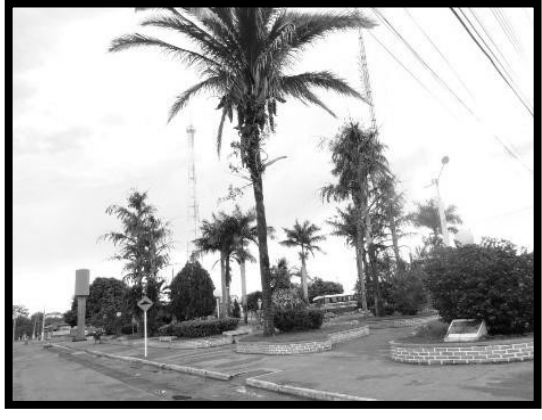

Figura 9: Praça da Torre na zona urbana de Porto Esperidião.

Relativo à estrutura da paisagem municipal constatou-se no período analisado que o uso antrópico contribuiu para da fragmentação da vegetação natural (Figura 10 e Tabela 3), observado pelo tamanho de área dos fragmentos. De acordo com Saunders et al. (1991) remanescentes de área pequena apresentam frágeis padrões de sustentabilidade ao longo do tempo, pois tendem a apresentar poucos indivíduos de uma mesma população, o que pode aumentar o declínio desta, resultando na perda da biodiversidade e insustentabilidade do fragmento.

Esse resultado evidência a fragmentação da paisagem, que acarreta no isolamento das formações e populações remanescentes, alterações nos fluxos gênicos, intensificação das competições, alterações da estrutura e qualidade de habitats, extinções de espécies e perda de biodiversidade (METZGER, 2001; BIERREGAARD et al., 1992; PRIMACK; RODRIGUES, 2001).
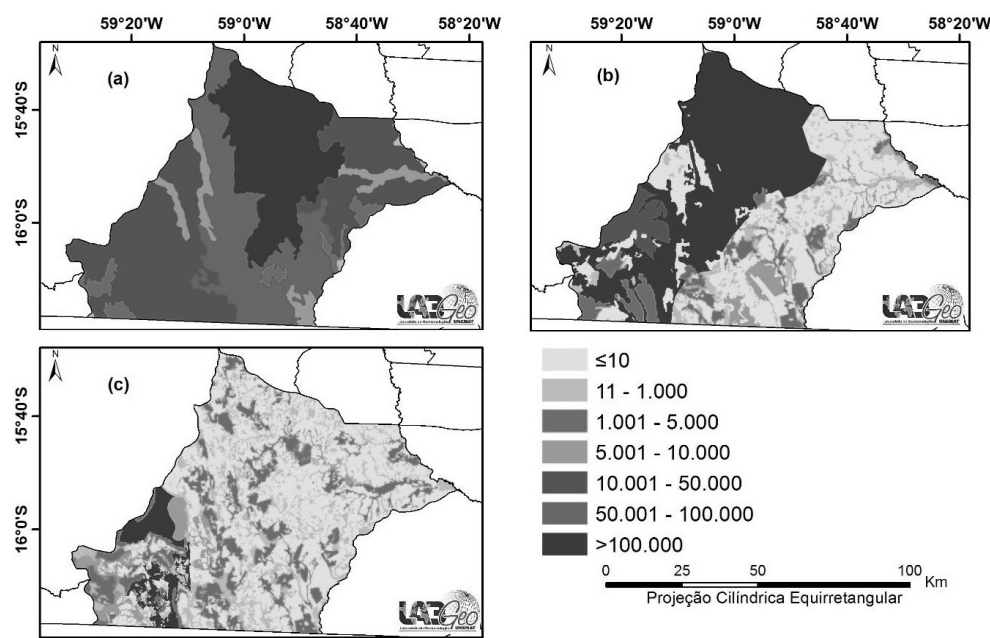

Figura 10: Área dos fragmentos florestais nos anos de 1982(a), 2002(b) e 2011(c) no município de Porto Esperidião/MT.

A modificação da paisagem pode ser observada nas principais formações vegetacionais, pois a Floresta aluvial, que em 1982 apresentava 15.093 ha passou em 2002 para 14.877 ha e em 2011 para 69.441 ha. O aumento entre 2002 e 2011 pode ser atribuído ao cumprimento da legislação ambiental - Lei № 7.803/89 (BRASIL, 1989), que prevê a conservação das diversas formações vegetais que ocorrem nas margens de rios e córregos. 
Tabela 3: Número de fragmentos florestais em relação á classes de tamanho.

Classes

$\geq 10$ ha

11-1.000 ha

1.001-5.000 ha

5.001-10.000 ha

10.001 - 50.000 ha

50.001-100.000 ha

$>100.000$ ha
1982

2002

2011

$\begin{array}{lrrr} & 1 & 317 & 403 \\ & 7 & 255 & 611 \\ & 7 & 28 & 3 \\ & 6 & 3 & - \\ & 4 & 1 & - \\ & 7 & & 2 \\ \text { Total } & 2 & 1 & \mathbf{1 0 2 4}\end{array}$

A classe Savana florestada foi a formação vegetal que sofreu maior supressão em 29 anos, sendo que em 1982 totalizava 206.497 ha, em 200234.159 ha e em 201131.929 ha. O total de Savana/Floresta estacional decidual em 2002 foi de 249.735 ha e em 2011 de 154.402 ha, comprometendo populações vegetais e animais. Segundo McGarigal e Marks (1995) quanto menor for o tamanho fragmentos, mais fragmentada é a paisagem, comprometendo a sobrevivência de muitas populações de espécies animais e vegetais em pequenos fragmentos, pela escassez de recursos alimentares, dificuldade de acesso a parceiros sexuais e aumento da suscetibilidade a ações antrópicas.

Tabela 4: Métricas referentes às classes de cobertura vegetal e uso da terra referente ao de 1982, 2002 e 2011.

\begin{tabular}{|c|c|c|c|c|c|c|c|c|c|c|c|c|}
\hline \multirow[b]{2}{*}{ Formação } & \multicolumn{4}{|c|}{1982} & \multicolumn{4}{|c|}{2002} & \multicolumn{4}{|c|}{2011} \\
\hline & $\mathrm{CA}(\mathrm{Ha})$ & NP & CIRCLE_MN & $\begin{array}{c}\text { ENN_MN } \\
(\mathrm{Km})\end{array}$ & $\mathrm{CA}(\mathrm{Ha})$ & NP & CIRCLE_MN & $\begin{array}{c}\text { ENN_MN } \\
(\mathrm{Km})\end{array}$ & $\mathrm{CA}(\mathrm{Ha})$ & NP & CIRCLE_MN & $\begin{array}{c}\text { ENN_MN } \\
(\mathrm{Km})\end{array}$ \\
\hline Floresta aluvial & $15.093,72$ & 7 & 0,7658 & 2,89 & $14.877,00$ & 32 & 0,8455 & 16,81 & $69.441,21$ & 380 & 0,7325 & 2,56 \\
\hline Floresta submontana & $111.857,04$ & 2 & 0,5024 & 0,26 & - & - & - & - & - & - & - & - \\
\hline Savana arborizada & - & - & - & - & $17.683,38$ & 9 & 0,6213 & 54,12 & $21.249,99$ & 71 & 0,6354 & 5,45 \\
\hline Savana florestada & $206.497,00$ & 5 & 0,7043 & 3,96 & $34.159,14$ & 115 & 0,5894 & 6,73 & $31.929,21$ & 150 & 0,5937 & 7,43 \\
\hline Savana arborizada com floresta da galeria & $112.283,73$ & 6 & 0,6932 & 2,35 & $9.787,14$ & 26 & 0,7197 & 16,18 & - & - & - & - \\
\hline Savana arborizada sem floresta de galeria & $122.861,16$ & 5 & 0,6355 & 2,88 & $23.572,17$ & 91 & 0,6464 & 8,25 & - & - & - & - \\
\hline Savana gramíneo-lenhosa & - & - & - & - & 756,99 & 5 & 0,5747 & 0,97 & - & - & - & - \\
\hline Savana parque & $12.308,85$ & 3 & 0,6235 & 18,76 & $42.118,02$ & 15 & 0,6243 & 12,57 & - & - & - & - \\
\hline Savana/Floresta estacional decidual & - & - & - & - & $249.735,06$ & 24 & 0,6540 & 6,74 & $154.402,02$ & 479 & 0,6704 & 7,11 \\
\hline Agropecuária & - & - & - & - & $42.143,04$ & 33 & 0,6630 & 19,71 & $177.615,73$ & 407 & 0,6274 & 1,83 \\
\hline Áreas degradadas por mineração & - & - & - & - & - & - & - & - & 262,35 & 3 & 0,6828 & 3,89 \\
\hline Pecuária & - & - & - & - & $146.817,54$ & 59 & 0,6673 & 2,90 & $123.858,36$ & 164 & 0,6251 & 2,03 \\
\hline Influência urbana & - & - & - & - & 210,69 & 1 & 0,5735 & N/A & 50,04 & 7 & 0,7277 & 4,00 \\
\hline Corpos d'água & - & - & - & - & - & - & - & - & $2.092,59$ & 63 & 0,6249 & 17,86 \\
\hline
\end{tabular}

Em relação a forma de fragmento, fragmentos com valores $>0,8$ são considerados arredondados, menos sujeitos a efeito de borda. No ano de 1982 as classes de Floresta aluvial, Savana florestada, Savana arborizada com floresta da galeria, Savana arborizada sem floresta da galeria e Savana parque apresentaram tendência moderadamente alongada, ou seja, estão mais sujeitos a efeitos de borda (Tabela 4), principalmente a Floresta submontana. Em 2002 a maioria das classes florestais apresentaram forma moderadamente alongada, entretanto nesse ano a classe Floresta Aluvial apresentou forma arredondada. No ano de 2011 todas classes apresentaram forma moderadamente alongada. Assim sendo, mesmo com o aumento do uso, nos anos investigados as classes vegetais estiveram menos sujeitas ao efeito de borda. Segundo Pirovani et al. (2014), a forma dos fragmentos reflete a relação entre área e borda, em que fragmentos de formatos mais regulares têm a razão borda área minimizada e, portanto, o centro da área está mais distante das bordas que são áreas protegidas dos efeitos negativos da borda, contribuindo para o equilíbrio do ecossistema. 
Referente a distância entre os fragmentos, em 1982 a classe Savana parque apresentou o maior valor, $18 \mathrm{~km}$, ou seja, seus fragmentos são os que estão mais distantes uns dos outros, enquanto a distância dos fragmentos das demais classes não excederam 4 km; em 2002 a maior distância registrada foi para a classe Savana Arborizada (54 km), sendo que a Savana gramíneo-lenhosa apresentou 0,97 km, constituindo os fragmentos que se encontram mais próximos uns dos outros. De acordo com Ferraz et al. (2005), um dos efeitos mais preocupantes da supressão da vegetação é o aumento na distância dos fragmentos florestais, que impedem o deslocamento da fauna entre as áreas, comprometendo com isso toda a biodiversidade regional.

\section{CONCLUSÃO}

Concluiu-se que no período investigado entre os anos de 1982 e 2011 a vegetação natural de Porto Esperidião foi suprimida principalmente em função do desenvolvimento da atividade agropecuária, acarretando diminuição na vegetação dos biomas presentes e aumento no número de fragmentos, consequentemente reduzindo a biodiversidade de fauna e flora e impactando a conservação ambiental.

No contexto geral da paisagem analisada, vale destacar que a influência antrópica é mais acentuada na porção oeste do município, devido aos tipos de uso da terra. Assim, a interação entre a dinâmica natural e a antrópica torna-se condição essencial para que se verifiquem processos degradação do meio ambiente.

O uso das geotecnologias foi eficiente nesse estudo, visto que os resultados gerados podem orientar as discussões sobre a criação do plano diretor do município e o aperfeiçoamento da legislação ambiental. Assim, sugere-se que sejam criadas estratégias de conservação que promovam a criação de Corredores Ecológicos, possibilitando a locomoção da fauna e troca de genes da flora, possibilitando a manutenção da biodiversidade, especialmente porque o município comporta o Parque Serra de Santa Bárbara.

\section{AGRADECIMENTOS}

Produção vinculada ao projeto de pesquisa "Modelagem de indicadores ambientais para a definição de áreas prioritárias e estratégicas à recuperação de áreas degradadas da região sudoeste de Mato Grosso/MT", vinculado à Sub-rede de estudos sociais, ambientais e de tecnologias para o sistema produtivo na região sudoeste mato-grossense - REDE ASA, financiada no âmbito do Edital MCT/CNPq/FNDCT/FAPs/MEC/CAPES/PRO-CENTRO-OESTE № 031/2010.

Ao Conselho Nacional de Desenvolvimento Científico e Tecnológico - CNPq pela concessão da bolsa de Iniciação Científica e a Coordenação de Aperfeiçoamento de Pessoal de Nível Superior - CAPES pela bolsa de mestrado. $\mathrm{O}$ autor agradece a prefeitura municipal de Porto Esperidião pela contribuição material para realização da pesquisa de campo.

\section{REFERÊNCIAS}

ABREU, S.. Planejamento Governamental: a sucedo no espaço mato-grossense. Tese (Doutorado em Geografia) Universidade de São Paulo, São Paulo, 2001.
ALVES, D. S.. O processo de desmatamento na Amazônia. Modelos e cenários para a Amazônia: o papel da ciência. Parcerias estratégicas, Brasília, v.6, n.12, p.259-275, 2001 
ANDRADE, L. N. P. S.; SOUZA, C. A.. Transformações espaçotemporal do uso do solo da sub-bacia hidrográfica do córrego das Pitas. Revista Eletrônica da Associação dos Geógrafos Brasileiros, Três Lagoas, v.5, n.8, p.23-25, 2008.

BERTRAND, G.. Paisagem e geografia física global: esboço metodológico. Caderno de Ciências da Terra, Curitiba, n.13, p.1-27, 1971.

BIERREGAARD, R. O.; LOVEJOY, T. E.; KAPOS, V.; SANTOS, A. A.; HUTCHINGS, R. W.. The biological dynamics of tropical rain forest fragments. Bioscience, Londres, v.42, n.1, p.859866, 1992. DOI: http://doi.org/10.2307/1312085

BOHRER, C. B. A.. Vegetação, paisagem e o planejamento do uso da terra. Geographia, Rio de Janeiro, v.2, n.4, p.103-120, 2000.

BRASIL. Lei $\mathbf{n} .12 .727$ de 17 de outubro de 2012. Institui o Código Florestal. Brasília: DOU, 2012.

BRASIL. Lei $\mathbf{n} . \mathbf{7 . 8 0 3}$ de 18 de julho de 1989. Altera a redação da Lei $n$ ㅇ 4.771, de 15 de setembro de 1965, e revoga as Leis nos 6.535, de 15 de junho de 1978, e 7.511, de 7 de julho de 1986. Brasília: DOU, 1989.

BRASIL. Ministério das Minas e Energia. Projeto Radam Brasil. Folha SD 21 Cuiabá; geologia, geomorfologia, pedologia, vegetação e uso potencial da terra. Rio de Janeiro: 1982a.

BRASIL. Ministério das Minas e Energia. Projeto Radambrasil. Folha SE 21 Corumbá e parte da folha SE. 20; geologia, geomorfologia, pedologia, vegetação e uso potencial da terra. Rio de Janeiro: 1982b.

BRASIL. Ministério do Meio Ambiente. Relatório ProbioPantanal. Brasília: MMA, 2007.

CÂMARA, G.; SOUZA, R. C. M.; FREITAS, U. M.; GARRIDO, J.. SPRING: Integrating remote sensing and GIS by objectoriented data modeling. Computers \& Graphics, São José dos Campos, v.20, n.3, p.395-403, 1996. DOI: http://doi.org/10.1016/i.cag.2016.04.004

CUNHA, J. M. P.. Dinâmica migratória e o processo de ocupação do Centro-Oeste brasileiro: o caso de Mato Grosso. Revista Brasileira de Estudo de População, Rio de Janeiro, v.23, n.1, p.87-107, 2006.

CUNHA, S. B.; GUERRA, A. J. T.. A Questão ambiental: diferentes abordagens. Rio de Janeiro: Bertrand Brasil, 2003.

ESRI. ArcGis advanced: realease 10.5. Redlands: Environmental Systems Research Institute, 2017.

FERRAZ, S. F. B.; VETTORAZZI, C. A.; THEOBALD, D. M.; BALLESTER, M. V.. Landscape dynamics of Amazonian deforestation between 1984 and 2002 in central Rondônia, Brazil: assessment and future scenarios. Forest Ecology and Management, v.204, n.1, p.67-83, 2005. DOI: http://doi.org/10.1016/J.Foreco.2004.07.073

GONÇALVES, A. B.; MAECATTI, G. E.; RIBEIRO, C. A. A. S.; SOARES, V. P.; MEIRA NETO, J. A. A.; LEITE, H. G.; GLERIANI, J.
M.; LANA, V. M. Mapeamento das áreas de preservação permanente e identificação dos conflitos de uso da terra na sub-bacia hidrográfica do Rio Camapuã/Brumado. Revista Árvore, Viçosa, v.36, n.4, p.759-766, 2012. DOI: http://dx.doi.org/10.1590/S0100-67622012000400017

IBGE. Instituto Brasileiro de Geografia e Estatística. Censo Agropecuário em 2006. Rio de Janeiro: IBGE, 2006.

IBGE. Instituto Brasileiro de Geografia e Estatística. Censo demográfico 2012: Resultados do Universo. Rio de Janeiro: IBGE, 2013.

IBGE. Instituto Brasileiro de Geografia e Estatística. Censo demográfico 1992: Resultados do Universo. Rio de Janeiro: IBGE, 2013.

IBGE. Instituto Brasileiro de Geografia e Estatística. Manual técnico da vegetação brasileira. Rio de Janeiro: IBGE, 2012.

MATO GROSSO (Estado). Secretaria de Estado e Planejamento e Coordenação Geral. Anuário Estatístico de Mato Grosso. Cuiabá: SEPLAN-MT, 2012.

MCGARIGAL, K.; MARKS, B. J.. Fragstats: spatial patterns analysis program for quantifiying landscape structure. Portland: USDA, Forest Service, Pacific Northwest Research Station, 1995.

MECHI, A.; SANCHES, D. L.. Impactos ambientais da mineração no Estado de São Paulo. Estudos Avançados, São Paulo, v.24, n.68, p.209-220, 2010. DOI: http://dx.doi.org/10.1590/S0103-40142010000100016

METZGER, J. P.. O que é Ecologia de Paisagens?. Biota Neotropica, São Paulo, v.1, n.1, p.1-9, 2001.

MIRANDA, M. R. S.; NEVES, L. F.; KREITLOW, J. P.; NEVES, S. M. A. S.; NEVES, R. J.. Queimadas no município matogrossense de Cáceres e as mudanças na cobertura vegetal e uso da terra. In: SIMPÓSIO DE GEOTCNOLOGIAS NO PANTANAL, 5. Anais. Campo Grande: INPE, 2014.

MIRANDA, M. R. S.; NEVES, S. M. A. S. N.; NEVES, R. J.. Análise, subsidiada nas geotecnologias, do uso da terra e da cobertura vegetal na região sudoeste mato-grossense, contida na Bacia Amazônica. In: SIMPÓSIO BRASILEIRO DE SENSORIAMENTO REMOTO, 15. Anais. Foz do Iguaçu: INPE, 2013.

NEVES, L. F.; MIRANDA, M. R. S.; NEVES, S. M. A. Mapeamento e análise, subsidiadas nas geotecnologias, da ocorrência de queimadas na região sudoeste Matogrossense, contida na Bacia Amazônica. In: SIMPÓsıO BRASILEIRO DE SENSORIAMENTO REMOTO, 17. Anais. João Pessoa: INPE, 2015.

PAIVA, S. L. P.; KREITLOW, J. P.; NEVES, S. M. A. S.; NEVES, R. J.; MUNIZ, C. C.. Sistemas de Informação Geográfica e Sensoriamento Remoto aplicado na análise de conflito de uso da terra na Bacia Ribeirão Jacobina-Pantanal Matogrossense. In: SIMPÓSIO DE GEOTECNOLOGIAS NO PANTANAL, 5. Anais. Campo Grande: INPE, 2014.

PIROVANI, D. B.; SILVA, A. G.; SANTOS, A. R.; CECÍLIO, R. A.; GLERIANI, J. M.; MARTINS, S. V.. Análise espacial de 
fragmentos florestais na Bacia do Rio Itapemirim, ES. Revista Árvore, Viçosa, v.38, n.2, p.271-281, 2014. DOI: http://dx.doi.org/10.1590/S0100-67622012000400017

PRIMACK, R. B.; RODRIGUES, E.. Biologia da conservação. Londrina, 2001.

SANTOS, S. A.; COSTA, C.; SOUZA, G. S.; POTT, A.; ALVAREZ, J. M.; MACHADO, S. R.. Composição Botânica da Dieta de Bovinos em Pastagem Nativa na Sub-Região da Nhecolândia, Pantanal. Revista Brasileira de Zootecnia, Viçosa, v.31, n.4, p.1648-1662, 2002. DOI: http://dx.doi.org/10.1590/S1516$\underline{35982002000700007}$

SAUNDERS, D. A.; HOBBS, R. J.; MARGULES, C. R.. Biological consequences of ecosystem fragmentation: a review.
Conservation Biology, v.5, n.1, p.18-34, 1991. DOI: http://doi.org/10.1111/cobi.12790

SCHNEIDER, S.; TARTARUGA, I. G. P.. Território e Abordagem Territorial: das referências cognitivas aos aportes aplicados à análise dos processos sociais rurais. Raízes, Campina Grande, v.23, n.1, p.99-116, 2004.

TARIFA, J. R.. Mato Grosso: Clima: análise e representação cartográfica. Cuiabá: Entrelinhas, 2011.

VELOSO, H. P.; RANGEL FILHO, A. L. R.; LIMA, J. C. A.. Classificação da vegetação brasileira, adaptada a um sistema universal. Rio de Janeiro: IBGE, 1991.

VOLOTÃO, C. F. S.. Trabalho de análise espacial: Métricas do Fragstats. São José dos Campos: INPE. 1998. 